\title{
Dispelling a few false-positives: A reply to MacGregor and McNamee on doping
}

\author{
Brent Michael Kious
}

Published online: 5 February 2011

(C) The Author(s) 2011. This article is published with open access at Springerlink.com

\begin{abstract}
McGregor and MacNamee recently, in this journal, offered several criticisms of an earlier article in which I attempted to refute a number of arguments for the claim that doping in sports is morally wrong. Their criticisms are numerous, but focus on four domains. First, they sketch a view on which the risk profiles of different sports may make doping permissible in some and impermissible in others. Second, they suggest that my criticisms of safety-based arguments assume that doping opponents are bent on harm elimination, rather than harm management. Finally, they offer two methodological criticisms, the first pertaining to my use of analogical arguments, and the second pertaining to the general difficulties of making revisionist arguments in ethics. I defend my criticisms of safety-based arguments by showing that these do not rest on the assumptions McGregor and MacNamee attribute to me and by noting that their own view about the variable relevance of safety considerations is underdeveloped. As for their methodological arguments, I endeavor to show that these are misplaced, in that they either rest on misinterpretations of my earlier article or on an excessively high standard for ethical argumentation.
\end{abstract}

Keywords Sports ethics · Doping · Moral methodology · Sports ·

Performance enhancement

Oskar MacGregor and Mike McNamee have recently, in this journal [1], offered several criticisms of an earlier article [2] where I argued that there is no clear reason for thinking that doping in sport is morally wrong. They have one overarching

B. M. Kious $(\bowtie)$

UCLA Medical Scientist Training Program, The David Geffen School of Medicine at UCLA, 23-385 Center for the Health Sciences, Box 957041/MC:704117, Los Angeles, CA 90095-7041, USA

e-mail: bkious@mednet.ucla.edu 
criticism of my article that floats on three more particular complaints. Of these, one is substantive, and two others are methodological. Here, I respond to their concerns. I begin by examining the overarching criticism and then turn to the more particular objections.

Briefly, MacGregor and McNamee's overarching criticism is that my article "oversimplifies ... a complex issue to an extent that renders [my] attack on the antidoping arguments unconvincing ... [T] he vast field referred to by the catch-all term 'sports' has such internal disparity as to render any attempts to turn the issue into a simple 'yes to doping' or 'no to doping' problematic" [1, p. 402].

Though the problems with this accusation will be more apparent once I have examined MacGregor and McNamee's specific objections, there are several difficulties with it even prima facie. One motivation for my earlier article was, in fact, to reveal part of the complexity that these two authors mention, which I felt had not been adequately appreciated within the anti-doping movement. It was not my intention to offer a simplistic "yes to doping" argument but, rather, to show that the more common objections to doping are unpersuasive- that the moral terrain surely is more complicated than it first seems. I did not, in the article, consider whether doping could have different moral valences in different sports because I was aiming to address positions that are commonly held, which this one is not. Moreover, I left open the possibility that there may be more nuanced arguments I did not address that show why doping, either generally or within specific sports, is morally wrong.

As for whether sports, as a group, have "such internal disparity" as to render inapt the general question of whether doping is morally wrong, it is doubtful that MacGregor and McNamee show this. The only dimension where they address differences between sports that could affect the permissibility of doping is safety. They observe that different sports involve different levels of risk (ping-pong is considerably safer than professional cycling), and say that this could be a reason to treat doping in these sports differently. Still, they provide no argument to make good on this possibility. Likewise, they say little to nothing about other reasons (such as considerations of dignity or justice) to regard doping as wrong, and so, do not show that broad "yes to doping" or "no to doping" claims are unjustifiable.

Now I wish to turn to MacGregor and McNamee's more particular worries. Their substantive criticism concerns my views about safety and has two arms. First, they suggest that my arguments assumed that doping's opponents are bent on eliminating all risks to athletes rather than simply managing them [1]. To that extent, they suggest, I was attacking a straw man. Society clearly thinks that some safety measures in sports, such as helmets in cycling, are reasonable. It may therefore be that limiting or eliminating doping is reasonable in the same way. The second arm is their aforementioned suggestion that because sports involve different risks, there may be more reason to limit doping in some sports than in others, so that one cannot say generally that doping is permissible or wrong [1].

There are several responses to make. First, I should note that my argument about safety did not assume that doping's opponents desire harm elimination. The argument was that since many sports tolerate substantial levels of risk related to usual practice and competition, and since many sports-or their characteristics that engender risk-are morally permissible, the fact that doping involves risks does not 
by itself show that it is morally wrong. I did suggest that if safety were of overriding concern, this would commit us to abandoning all risky sports; but this was obviously a reductio of the notion that risk necessitates wrongness and not, as MacGregor and McNamee think, a "description of a philosophically refined anti-doping position" [1, p. 404].

And while I happily concede that harm management in sports is reasonable and even that it could include efforts to curtail doping, this in no way contradicts my earlier point. One need not regard something as morally wrong in order to restrict it: moral considerations are not the only grounds for rules. It is not, for example, clearly wrong to drink sugary beverages, but it may be reasonable to limit persons' access to them and to create a system of incentives (e.g., taxes) that reduces their consumption.

One might say that I am making a distinction without any difference by separating moral wrongness from other sorts of impermissibility. But while I cannot here speak to the question of what constitutes morality, there are a variety of reasons to ask whether doping is morally wrong per se. First, conventional attitudes about doping treat it as something that is deeply wrong rather than as something that is merely unwise. Second, current anti-doping strategies incorporate severe punishments for violators. But if a system involving such punishments is to be justified, a moral justification should be required. It would be absurd to ruin athletes' lives to promote their well-being, just as it would be absurd to imprison someone for a year because he failed to wear his seatbelt.

A bit more should be said regarding MacGregor and McNamee's suggestion that doping may have a different status in different sports, depending on their other risks. First, it is unclear how or why the difference between sports would have this effect. The authors do not specify whether one should be more tolerant of doping in sports that are very risky or less tolerant of it-both positions are prima facie reasonable. Second, this strategy would represent a weakening of the anti-doping position. Even if we were to tie imprudence to wrongness, to hold that doping should be treated differently in different sports would surely mean that some instances of doping are (considering safety only) morally permissible. Moreover, if the complexity of risk assessments were fully embraced, one would probably find that some types of doping should be broadly permitted. After all, some performance-enhancing drugs are safer than others. Albuterol, for example, is relatively innocuous in comparison to anabolic steroids. And even the most dangerous drugs are probably safe when used in moderation. A touch of EPO-enough to raise one's hematocrit from 45 to $50 \%$, for example - might not be especially dangerous, even though a large amount of EPO is dangerous indeed.

Next, I wish to consider the authors' methodological criticisms. The first was that my arguments relied too heavily on analogies. They find fault with this because analogies can fail where they are inapt or, instead, be misleading where there are multiple analogies to a case that have conflicting moral implications.

While MacGregor and McNamee's general worry about analogies is uncontroversial, their criticism of my article is misplaced. The argument that they hold up as an example of my inappropriate use of analogies was my suggestion that doping is not clearly wrongfully coercive [1]. In setting up their criticism, they focus on an 
example I used wherein one person imposes an unwanted decision on another: forcing him to choose between a cheap motel and an expensive resort by taking the last room at the inn. They try to undercut the force of this example by offering three analogies suggesting that doping is morally wrong, which invoked terrorism, paternalism, and college admissions [1]. That these analogies point to a different conclusion about doping than the one I reached, they suggest, demonstrates how analogies can be misleading. They also note that the analogy betwen doping and my example is likely to fail simply because the latter does not involve competition.

There is, though, a serious problem with this criticism: my argument about coercion was not analogical. The argument went as follows: I suggested that opponents of doping might think that it is wrong because it is coercive. I then asked what it means for something to be coercive and considered some candidate accounts. The first account identified coercion with the use of threats to elicit desired behavior from others. I pointed out that doping cannot be coercive in that respect since it does not involve threats and is not aimed at eliciting behavior from others. I then considered whether coercion is a matter of imposing unwanted choices on others (which is a feature of prototypical coercive actions, like muggings). But this, I said, cannot be a correct analysis of coercion generally since many unwanted choices are not coercive. Here, my example came into play: I impose an unwanted choice on you when I take the last room at the inn, so you must decide between the cheap motel and the expensive resort, but my doing so is neither coercive nor wrong. So the "analogy" that MacGregor and McNamee dismiss here was just a counterexample to a general theory of coercion, and their ability to produce analogies implying different conclusions is inconsequential, as is their concern that my counterexample had nothing to do with competition.

MacGregor and McNamee's concerns about analogies are more apt for my arguments about safety and distributive justice but fail in those cases too. The analogies I used there were quite strong, and in the article, I tried to ensure this. MacGregor and McNamee themselves accept the analogy between the risks of doping and the risks imposed by the traditional practices of many sports, conceding that this demonstrates an "inconsistency" in the thinking of many doping opponents. Likewise, their other analogies do not show that mine were misleading. To claim that considerations of safety do not clearly show that doping is morally wrong because many unsafe practices are morally permissible is importantly different from arguing that "terrorism is wrong, and terrorism imposes unwanted choices on people; doping imposes unwanted choices on people, so doping is wrong." 1 This difference is, again, that the former analogy functions like a counterexample to a universal generalization whereas the latter analogy implicitly derives a universal from an existential claim.

This brings us to MacGregor and McNamee's other methodological criticism. Throughout my article, I appealed to intuitions about what is and is not morally permissible. But, as MacGregor and McNamee write, "appeals to what is 'clearly'

\footnotetext{
1 The most compelling of the countervailing analogies that MacGregor and McNamee use is the case of college admissions, and it deserves some consideration both for the challenges it poses to an anti-antidoping position and for its own sake. But this is a separate issue that I do not have the space to address here.
} 
morally permissible or wrong in moral argumentation are contentious, particularly where one is attempting to argue against the status quo" [1, p. 405]. Again, they take issue with my argument about safety, especially my claim that it would be inconsistent to hold both that risk makes doping wrong and that various other risky practices are morally permissible. They note that this inconsistency does not alone imply that doping is permissible since it is open to opponents of doping to hold that these other activities are morally wrong.

This point about the logic of conditionals cannot be faulted. But I did not conclude that because various unsafe practices are (commonly regarded as) permissible, doping is also permissible. Instead, my point was that the argument that doping is wrong because it is unsafe ought to be regarded as inconclusive.

And though it would restore consistency for opponents of doping to argue that doping and more conventional risk-laden sporting practices are wrong because they are unsafe, this would be a costly retreat. It would, obviously, imply that society should disband or alter many popular professional sports, which is counterintuitive (indeed, this was the force of my reductio mentioned earlier). It might also have unsavory implications for other realms of conventionally permissible human activity. And it would require opponents of doping to overcome various argumentative hurdles, such as demonstrating that a certain degree of imprudence is morally wrong. Finally, the cost of abandoning a safety-based anti-doping argument is relatively minor: it is to concede not that doping is permissible but only that considerations of safety alone do not show it is wrong. So while the two authors are correct that opponents of doping could "bite the bullet" to avoid the inconsistency, this is more of a logical possibility than a practical one.

On a related note, MacGregor and McNamee suggest that I assume that riskladen sports are morally permissible simply because they are sports. As they say, "the ... inconsistency in arguing against the moral status quo with respect to doping while simultaneously seeking to maintain the moral status quo regarding the permissibility of certain sports ... points to an oversimplification of the vast family of sports. Membership in that family ... does not guarantee consensus on a specific sport's moral permissibility" [1, p. 409; italics added]. But this involves a misreading. I did not rely upon the claim that simply being a sport entails moral permissibility, nor even universal regard as morally permissible. That is implausible, since one can easily conceive of impermissible sports. Rather, my claim that many risk-laden sports (cycling, American football, etc.) are permissible is just based on the fact that, conventionally, they are individually regarded as permissible so that there is usually no question about whether they should be permitted.

Admittedly, the authors' plea for caution when attempting revisionist projects is well taken as a point about rhetoric. But it does not mean we should never press ahead into revisionism. Not all aspects of the moral status quo are on par. Too often in the history of moral thought have we leapt to condemn novel behaviors before carefully considering whether we have reason to do so. There was, for example, initially substantial resistance to in vitro fertilization, but now, few regard it as unconscionable. Similarly, there is increasing recognition of the moral legitimacy of homosexuality, though to many it once seemed anathema. In both cases, this reversal was wrought partially by careful arguments showing our concerns were 
misplaced. And, presumably, these arguments often depended upon appeal to other, seemingly clear, moral intuitions - indeed, what else could they have done? Nearly all philosophical arguments rely upon such appeals. It is hard to see why that reliance should seem irresponsible when we examine the moral legitimacy of doping.

There are a few other critical notes in MacGregor and McNamee's article that I might address, but the foregoing has touched upon the most compelling of them. I think I have shown that these-especially their methodological criticisms-are mainly founded upon misreadings or misunderstandings of my views. In future, I would hope to see the authors take up the challenge I set out by offering better demonstrations of the wrongness of doping, which address my earlier concerns in a substantive fashion. As they correctly note, the moral terrain surrounding doping is quite complicated, but they have said little here to help untangle that complexity.

Open Access This article is distributed under the terms of the Creative Commons Attribution Noncommercial License which permits any noncommercial use, distribution, and reproduction in any medium, provided the original author(s) and source are credited.

\section{References}

1. MacGregor, Oskar, and Mike McNamee. 2010. Philosophy on steroids: A reply. Theoretical Medicine and Bioethics 31: 401-410.

2. Kious, Brent M. 2008. Philosophy on steroids: Why the anti-doping movement could use a little enhancement. Theoretical Medicine and Bioethics 29: 213-234. 